\title{
PENYULUHAN BERBASIS MULTIMEDIA DALAM MENCEGAH PERILAKU SEKS PADA REMAJA DI SMU NEGERI 11 PEKANBARU
}

\author{
Susi Erianti ${ }^{1)}$, Dian Roza Adila ${ }^{1)}$ \\ 1)Program Studi Keperawatan STIKes Hang Tuah Pekanbaru \\ email: susi_eriyanti@yahoo.com; adila_skep@ymail.com
}

\begin{abstract}
ABSTRAK
Remaja adalah perubahan dari masa anak-anak menuju dewasa, hal ini biasanya sering disebut dengan pubertas. Perilaku sifat negatif dapat di kurangi dengan pembinaan pada diri seseorang. Apabila perilaku seks ini dilakukan secara berulang-ulang untuk mencapai kepuasan seksual dan merugikan diri sendiri maupun orang lain disebut sebagai kelainan atau gangguan seksual. Tujuan dari pengabdian masyarakat ini adalah untuk meningkatkan pengetahuan dan pemahaman siswa/i dalam mencegah perilaku seks pada remaja. Instrument pengabdian ini menggunakan kuesioner dengan melakukan pre test dan post test pada 60 siswa/i SMUN 11 Pekanbaru yang kemudian dianalisis dengan menggunakan persentase. Penilaian capaian tujuan pengabdian masyarakat dilakukan secara deskriptif kuantitatif apakah ada kenaikan persentase dari nilai pre test dan post test. Hasil dari pengabdian masyarakat didapatkan adanya kenaikan nilai pre test (65\%) untuk tingkat pengetahuan siswa/i menjadi post test (87\%). Hal ini menunjukkan bahwa penyuluhan yang dilakukan dengan metode berbasis multimedia sangat efektif dalam meningkatkan pengetahuan siswa/i untuk memahami cara mencegah perilaku seks pada remaja karena penyuluhan dengan multimedia adalah suatu kombinasi data atau media untuk menyampaikan suatu informasi sehingga informasi yang tersaji lebih menarik. Untuk itu diharapkan adanya kegiatan yang terjadwal dari pihak sekolah untuk melakukan penyuluhan dengan berbasis multimedia sehingga informasi yang disampaikan kepada siswa/i lebih mudah dipahami.
\end{abstract}

Kata kunci: multimedia, perilaku seksual, remaja

\section{ABSTRACT}

Adolescence is a change from childhood to adulthood, this is called puberty. Behavior negative aspect can be reduced by coaching oneself. Sexual behavior is all behavior that is related to normal and abnormal sexual activity. If this sexual behavior is carried out repeatedly to achieve sexual satisfaction and harming oneself and others, it is referred to as a sexual disorder. The purpose of this project community service is to increase students' knowledge and understanding in preventing sexual behavior in adolescents. This project uses a questionnaire by conducting pre-test and post-test on 60 students of SMUN 11 Pekanbaru which were then analyzed using percentages. Evaluation of the achievement of community service objectives was carried out in a quantitative descriptive manner whether there was an increase in the percentage of the value of the pre test and post test. The result showed that an increasing of knowledge level from $65 \%$ into $87 \%$. This suggestion to the school is make a schedule to do education using multimedia based - counseling that can make students easier to understand about the education topic.

Key words: multimedia, sexual Behavior, youth 


\section{PENDAHULUAN}

Perilaku merupakan bentuk suatu respon yang timbul dari suatu stimulus seseorang yang kemudian diamati melalui tingkah laku baik secara langsung maupun tidak langsung (Emilia, 2008). Perilaku mempunyai sifat positif dan sifat negatif, perubahan sifat yang negatif dapat di kurangi dengan pembinaan dan perkembangan perilaku positif pada diri seseorang(Notoatmodjo, 2012). Perilaku seksual adalah semua tingkah laku yang berkaitan dengan seksual yang normal maupun tidak normal. Apabila perilaku seks ini dilakukan secara berulang-ulang untuk mencapai kepuasan seksual dan merugikan diri sendiri maupun orang lain disebut sebagai kelainan atau gangguan seksual (Kusmiran, 2012).

Perkembangan perilaku akan terlihat ketika seorang remaja mengalami proses perkembangan dan pertumbuhan. Remaja merupakan perubahan yang terjadi dan terlihat pada diri seseorang dari masa anak-anak dan selanjutnya akan menjadi dewasa. Batasan usia remaja dimulai dari remaja awal 11-13 tahun, remaja menengah 14-16tahun, dan remaja akhir 17-19 tahun. Remaja akan mengalami pubertas atau mengalami kematangan fisik dan seksualnya.Remaja juga akan mengalami perkembangan kepribadian dimana dia akan lebih bersifat mandiri, dapat memahami masalah yang dialami dan dapat terlibat didalam suatu kegiatan. Perkembangan sosial pada remaja terlihat ketika remaja mampu berinteraksi dengan lingkungannya baik individu maupun kelompok, perannya akan sangat berpengaruh dalam suatu kegiatan (Depkes RI , 2013).

Pada masa remaja keingintahuan tentang seksual sangat tinggi dan remaja biasanya mulai menyukai lawan jenis,untuk menarik perhatian lawan jenisnya, remaja akan melakukan berbagai hal untuk terlihat menarik seperti berdandan, mengedipkan mata, merayu, menggoda, dan berisiul. Semua tindakan yang berkaitan dengan seksual termasuk kedalam perilaku seksual, baik tingkah laku seksual yang normal maupun tidak yang bertujuan untuk mencapai kepuasan seksual baik dengan lawan jenis maupun sesama jenis seperti onani dan masturbasi (Emilia, 2008; Kusmiran, 2012).

Berdasarkan data yang ditemukan terkait perilaku seksual remaja maka hal ini harus mendapatkan perhatian dari setiap unsur yang ada. Salah satu hal yang bisa dilakukan adalah memberikan penyuluhan terkait pencegahan perilaku seksual remaja. Penyuluhan yang dilakukan menggunakan met ode yang menarik tetapi informasi yang ingin disampaikan harus dapat dimengerti dan dipahami oleh remaja. Salah satu tehnik yang digunakan adalah penyuluhan berbasis multimedia. Multimedia adalah media berbasis komputer dan sistem komunikasi yang memiliki peran untuk membangun, menyimpan, menghantarkan dan menerima informasi dalam bentuk teks, grafik, audio, video dan sebagainya selain itu multimedia merupakan penyatuan dua atau lebih media komunikasi seperti teks, grafik, animasi, audio dan video dengan ciri - ciri interaktivitas komputer untuk menghasilkan suatu presentasi yang menarik (Munir, 2012).

Berdasarkan uraian diatas maka penulis sangat tertarik untuk melakukan pengabdian masyarakat tentang pencegahan perilaku seksual remaja dengan menggunakan multimedia sehingga diharapkan remaja dapat memahami dampak dari perilaku seksual terhadap kesehatannnya. 


\section{TINJAUAN PUSTAKA}

WHO (2010) mencatat bahwa jumlah remaja didunia saat ini mencapai 1,2 milyar. Dalam perkembangannya remaja sangat rentan terhadap pengaruh lingkungan baik itu lingkungan sosial maupun budaya. Lingkungan yang tidak positif merupakan faktor resiko bagi remaja untuk terjebak dalam perilaku merokok, minum muniman keras, penggunaan narkoba, seks sebelum menikah, tawuran dan kriminal. Semua perilaku seksual remaja yang dianggap menyimpang ini sangat beresiko terhadap kesehatan dan keselamatan remaja (Kumalasari \& Andhyantoro, 2013)

Hasil penelitian Synovate Research pada remaja (14-19 tahun) tentang perilaku seksual remaja dari beberapa kota yang ada seperti jakarta, surabaya, yogyakarta dan medan didapatkan data bahwa rata - rata remaja tidak mempunyai pengetahuan yang khusus dan komprehensif terkait tentang seks, hal ini sangat beresiko remaja untuk melakukan tindakan - tindakan yang beresiko terhadap masalah kesehatan remaja. Sedangkan dari hasil penelitian Annisa Foundation yang melakukan penelitian pada siswa SMP dan SMU di Cianjur (Jabar) didapatkan bahwa 42,3\% pelajar telah melakukan hubungan seks yang pertama dibangku sekolah (BKKBN, 2015).

Multimedia dapat mengembangkan kemampuan indera dan menarik perhatian dan minat. Computer Technology Research (CTR), menyatakan bahwa orang hanya mampu mengingat $20 \%$ dari yang dilihat dan 30\% dari yang didengar, tetapi orang dapat mengingat $50 \%$ dari yang dilihat dan didengar dan $80 \%$ dari yang dilihat, didengar dan dilakukan sekaligus. Multimedia dapat menyajikan informasi yang dapat dilihat, didengar dan dilakukan, sehingga multimedia sangatlah efektif untuk menjadi alat dalam proses pemberian suatu informasi.

\section{METODE PELAKSANAAN}

Metode yang digunakan dalam kegiatan pengabdian ini adalah penyuluhan berbasis multimedia tentang cara mencegah perilaku seks pada remaja. Penyuluhan kesehatan ini menggunakan metode ceramah dengan tanya jawab serta menggunakan video dan power point untuk menyampaikan materi sehingga materi yang disampaikan lebih menarik dan lebih mudah dipahami oleh siswa/i. Capaian pada kegiatan adalah meningkatnya pengetahuan siswa/i tentang perilaku seks dan cara mencegah perilaku seks pada remaja. Tingkat pengetahuan siswa/i di ukur dengan pre-test dan post-test setelah mengikuti kegiatan. Kegiatan ini dikatakan berhasil jika nilai post test lebih tinggi dari nilai pre-test dengan nilai post-test mencapai $80 \%$. Sasaran pada kegiatan ini adalah remaja yang ada di SMU Negeri 11 Pekanbaru. 

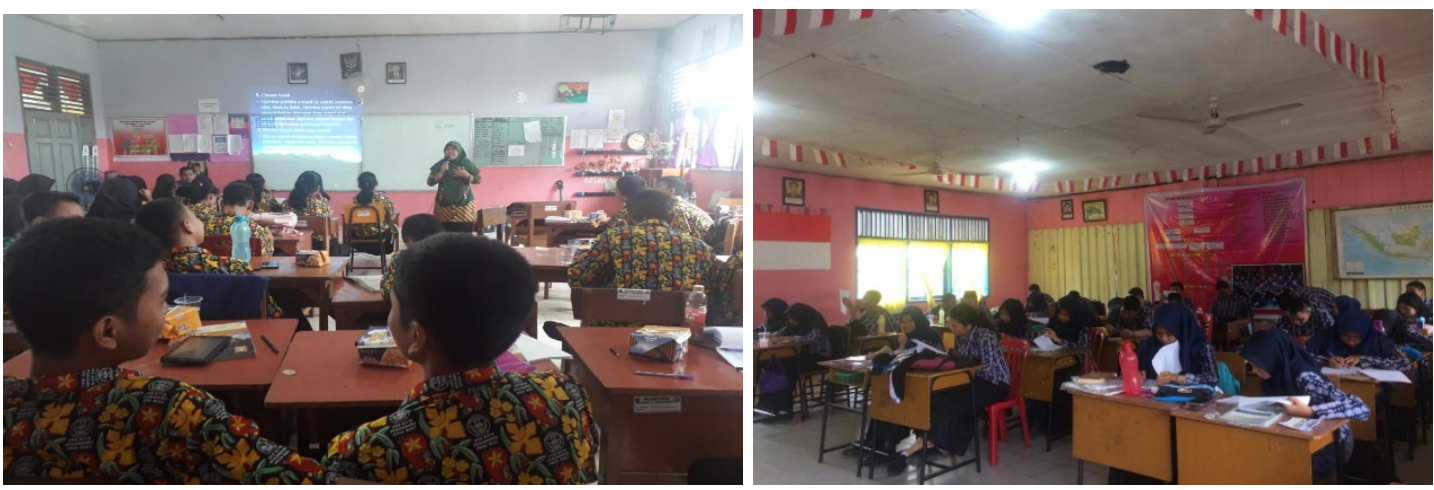

Gambar 1. Pelaksanaan Kegiatan Pengabdian

\section{HASIL DAN PEMBAHASAN}

Hasil kegiatan yang didapatkan dalam proses pengabdian masyarakat sesuai dengan tujuan pengabdian masyarakat adalah meningkatkan pengetahuan siswa/i tentang pencegahan perilaku seks yaitu dengan memaparkan materi tentang pencegahan perilaku seks pada remaja dengan berbasis multimedia yaitu power point dan video. Untuk menilai tingkat pengetahuan mahasiswa tentang pencegahan perilaku seks pada remaja maka dilakukan tes tertulis sebelum (pre test) dan setelah (post test) saat penyampaian materi oleh tim pengabmas PSIK STIKes Hang Tuah. Hasil pre test dan post test adalah sebagai berikut:

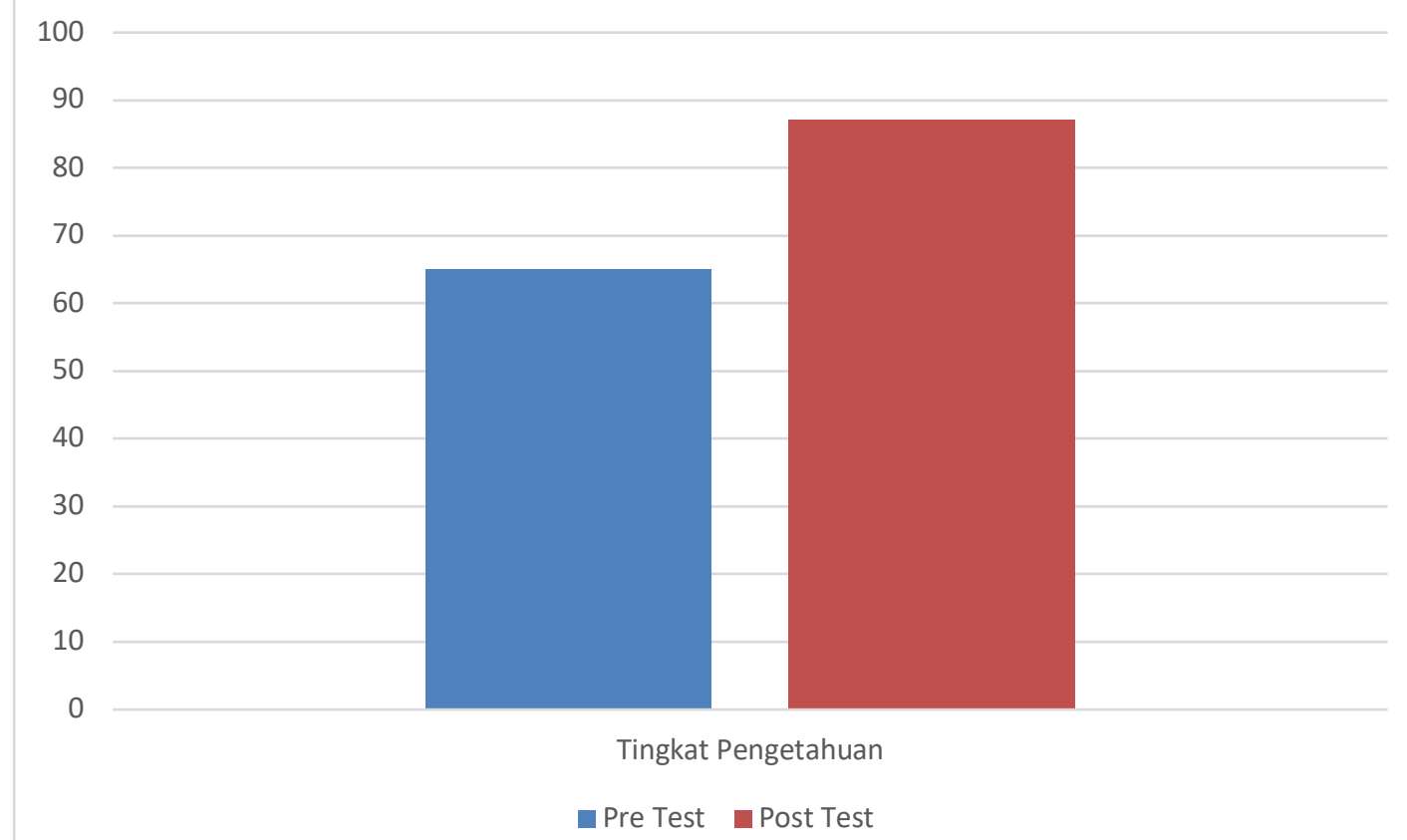

Gambar 2. Diagram Tingkat Pengetahuan Siswa/i Tentang Pencegahan Perilaku Seks Pada Remaja 
Dari hasil diagram tersebut dapat dilihat bahwa angka tingkat pengetahuan siswa/i terlihat ada kenaikan tingkat pengetahuan dari sebelum (pre test) sebanyak 65\% dan sesudah penyampaian materi (post test) sebanyak 87\%. Hal ini menunjukkan bahwa penyampaian materi penyuluhan tentang pencegahan perilaku seks pada remaja dengan menggunakan multimedia menunjukkan hasil adanya peningkatan pengetahuan siswa/i.

Dari hasil tersebut Tim Pengabmas PSIK STIKes Hang Tuah berharap siswa/i bisa termotivasi untuk tidak melakukan tindakan perilaku seks yang beresiko sehingga dengan pengetahuan yang baik siswa/i bisa terhindar dari perilaku yang dapat menyebabkan masalah kesehatan reproduksi pada remaja.

\section{Pembahasan Pelaksanaan Pengabdian Masyarakat}

Remaja adalah perubahan dari masa anak-anak menuju dewasa, hal ini biasanya sering disebut dengan pubertas. Pada masa remaja sudah mulai menunjukan perilaku dan interaksi dengan lingkungan sekitarnya. Perilaku merupakan bentuk suatu respon yang timbul dari suatu stimulus seseorang yang kemudian di aplikasikan melalui tingkah laku. Tingkah laku tersebut dapat dilihat secara langsung maupun tidak langsung. Masa remaja sudah bisa melakukan interaksi di luar lingkungan keluarganya sehingga remaja sangat rentan terjadi tindakan perilaku seks yang beresiko. ${ }^{[7,10]}$.Penelitian yang dilakukan oleh Destariyani dan Dewi (2015) menunjukan bahwa ada hubungan antara pengetahuan, lingkungan Keluarga, pengaruh teman sebaya, dan media informasi terhadap perilaku seks pada remaja (Destariyani \& Dewi, 2015).

Penyuluhan tentang pencegahan perilaku seks pada remaja berbasis multimedia pada siswa/i SMUN 11 Pekanbaru dilakukan dengan cara melakukan Pre Test dan Post test. Hasil dari penyuluhan didapatkan bahwa terjadi peningkatan pengetahuan siswa/i sebelum (pre test) sebanyak $65 \%$ meningkat menjadi $87 \%$ setelah (post test) penyampaian materi oleh Tim pengabmas PSIK STIKes Hang Tuah Pekanbaru. Pre Test adalah test yang diberikan sebelum pengajaran dimulai dengan tujuan untuk mengetahui sampai dimana penguasaan siswa terhadap bahan pengajaran yang akan diajarkan. Dalam hal ini fungsi pre test adalah untuk melihat sampai dimana keefektifan pengajaran. Sedangkan post test adalah test yang diberikan pada setiap akhir program satuan pengajaran. Tujuan post test adalah untuk mengetahui sampai dimana pencapaian siswa terhadap materi yang disampaikan setelah mengalami kegiatan pemebelajaran. Dari pernyataan diatas pelaksanaan pre test dan post test sangat direkomendasikan karena merupkan alat uji yang ringkas dan efektif dalam menilai tingkat pengetahuan siswa/i (Costa, 2014).

Penyuluhan yang diberikan menggunakan multimedia yaitu power point dan video. Multimedia adalah media berbasis komputer dan sistem komunikasi yang memiliki peran untuk membangun, menyimpan, menghantarkan dan menerima informasi dalam bentuk teks, grafik, audio, video dan sebagainya selain itu multimedia merupakan penyatuan dua atau lebih media komunikasi seperti teks, grafik, animasi, audio dan video dengan ciri - ciri interaktivitas komputer untuk menghasilkan suatu presentasi yang menarik (Munir, 2012).

Multimedia dapat mengembangkan kemampuan indera dan menarik perhatian dan minat. Computer Technology Research (CTR), menyatakan bahwa orang hanya mampu mengingat $20 \%$ dari yang dilihat dan $30 \%$ dari yang didengar, tetapi orang dapat mengingat $50 \%$ dari yang dilihat dan didengar dan $80 \%$ dari yang dilihat, didengar dan dilakukan 
sekaligus. Multimedia dapat menyajikan informasi yang dapat dilihat, didengar dan dilakukan, sehingga multimedia sangatlah efektif untuk menjadi alat dalam proses pemberian suatu informasi (Munir, 2012).

Dengan penggunaan multimedia informasi yang disampaikan menarik sehingga siswa/i tertarik dengan informasi yang disampaikan. Ketertarikan terhadap suatu informasi membuat siswa/i mengikuti dengan baik penyuluhan yang diberikan dan dengan demikian bisa meningkatkan pengetahuan siswa tentang pencegahan perilaku seks yang diberikan oleh Tim Pengabmas PSIK STIKes Hang Tuah.

\section{KESIMPULAN}

Media merupakan hal yang penting dalam melakukan penyuluhan kepada siswa/i karena media yang baik dan menarik akan memudahkan dalam penyampaian informasi. Tehnik yang digunakan dalam penyuluhan ini adalah penyuluhan berbasis multimedia. Multimedia adalah media berbasis komputer dan sistem komunikasi yang memiliki peran untuk membangun, menyimpan, menghantarkan dan menerima informasi dalam bentuk teks, grafik, audio, video dan sebagainya selain itu multimedia merupakan penyatuan dua atau lebih media komunikasi seperti teks, grafik, animasi, audio dan video dengan ciri - ciri interaktivitas komputer untuk menghasilkan suatu presentasi yang menarik. Dari hasil penyuluhan didapatkan adanya peningkatan pengetahuan siswa/i sebelum (pre test) sebanyak $65 \%$ meningkat menjadi $87 \%$ setelah (post test) penyampaian materi berbasis multimedia. Dengan demikian penyajian informasi dengan multimedia dapat menyajikan informasi yang dapat dilihat, didengar dan dilakukan, sehingga multimedia sangatlah efektif untuk menjadi alat dalam proses pemberian suatu informasi.

\section{SARAN}

Untuk Tim pengabdian masyarakat berikutnya diharapkan untuk melibatkan pihak sekolah dalam proses penyuluhan agar pihak sekolah dapat membuat program rutin kepada siswa/i dalam memberikan penyuluhan berbasis multimedia dan membentuk tim penyuluh sekolah agar sekolah bisa memberikan penyuluhan secara mandiri.

\section{UCAPAN TERIMA KASIH}

Penulis mengucapkan terima kasih kepada STIKes Hang Tuah Pekanbaru atas dukungan yang diberikan kepada kami Tim Pengabdian Masyarakat sehingga kami bisa meyelesaikan kegiatan pengabdian masyarakat ini dengan baik, selain itu kami juga mengucapkan terima kasih kepada kepala sekolah SMU Negeri 11 Pekanbaru atas izin dan kesempatan yang diberikan kepada kami untuk memberikan penyuluhan dalam rangka pelaksanaan pengabdian masysrakat. 


\section{DAFTAR PUSTAKA}

[5]. BKKBN, Kalangan Remaja Kurang Peroleh Informasi Seks Tuntas. Diakses dari http: //www.bkkbn.go.id 12 Februari 2016

[6]. Costa, M, (2014). Choosing the Right Assessment Method: Pre-Test/Post-Test Evaluation, Boston University, Cabrillo Colleges SLO websites 12/17/2013; Revised 4/23/2014.

[7]. Depkes RI . (2013). Materi Pelayanan Kesehatan Peduli Remaja (PKPR).Jakarta

[8]. Destariyani, Ratna \& Dewi, Ratna. (2015). Faktor - faktor yang Berhubungan dengan Perilaku Seksual Pranikah pada Remaja SMPN Negeri 1 Talang Empat Kabupaten Benkulu Tengah. Jurnal IKESMA, Vol 11. No.01

[9]. Emilia, O. (2008). Promosi Kesehatan Dalam Lingkup Kesehatan Reproduksi. Yogyakarta : Pustaka Cendeka.

[10]. Kumalasari, I \& Andhyantoro, I . (2013). Kesehatan reproduksi untuk mahasiswa kebidanan dan keperawatan. Jakarta: Salemba Medika.

[11]. Kusmiran, E. (2012). Kesehatan Reproduksi Remaja dan Wanita. Jakarta: Salemba Medika.

[12]. Munir. (2012). Konsep Multimedia dan Aplikasi Dalam Pendidikan. Alfabeta. Bandung

[13]. Notoatmodjo, S. (2012). Promosi Kesehatan dan Perilaku Kesehatan. Jakarta: Rineka Cipta.

[14]. Pratama, B. A. \& Ratna, S. (2015). Efek penggunaan jejaring sosial terhadap perilaku seks remaja. Indonesia Journal On Medical Science. Volume 2. Diperoleh dari http://ejournal.ijmsbm.org 